\title{
Burnout among Palestinian Nurses Working in Governmental and Private Hospitals at Nablus District
}

\author{
Imad Abukhader, Khadija Abukhader, Omnya Naser, Yasmin Saeed, Akram Maliashe \\ Faculty of Nursing, Arab American University, Jenin, Palestine \\ Email:imad.abukhader@aaup.edu
}

How to cite this paper: Abukhader, I., Abukhader, K., Naser, O., Saeed, Y., \& Maliashe, A. (2020). Burnout among Palestinian Nurses Working in Governmental and Private Hospitals at Nablus District. Open Journal of Social Sciences, 8, 1-11. https://doi.org/10.4236/jss.2020.87001

Received: May 26, 2020

Accepted: June 30, 2020

Published: July 3, 2020

Copyright () 2020 by author(s) and Scientific Research Publishing Inc. This work is licensed under the Creative Commons Attribution International License (CC BY 4.0).

http://creativecommons.org/licenses/by/4.0/ (c) (i) Open Access

\begin{abstract}
Background: Burnout is a syndrome that typically characterized by emotional exhaustion, depersonalization, and reduced personal accomplishment. World Health Organization (WHO) recognized burn out as a mental health problem that defined as "a syndrome conceptualized as resulting from chronic workplace stress that has not been successfully managed. Objectives: The study aimed to assess burnout among nurses and to determine the difference, if any, in burnout of nurses working in Government and Private Hospitals. Methods: A cross-sectional, descriptive, correlational design was used to assess burnout among nurses, and to explore the difference burnout level among nurses at four hospitals in Nablus district which are Nablus Specialty Hospital, Specialized Arab Hospital, which are private hospitals, in addition to Al Watani Hospital and Rafidia Surgical Hospital which are governmental hospitals. Out of the 420 nurses in Nablus district hospitals, 195 were selected as study participants using stratified random sampling. Data collection tools: A self-administered questionnaire of three parts: Demographic information, Occupation information and the Maslach Burnout Inventory (MBI) was used to measure burnout. Statistical Analysis: Descriptive and inferential statistics were employed in the analysis using the Statistical Package for the Social Sciences software (SPSS version 22). Frequencies were used to describe the demographic characteristics and work conditions. In addition to paired t-test and ANOVA to compare the means between governmental and private hospitals, and to determine any significance inferential statistics were generated at alpha level of $P<0.05$. Results: The majority of the participated nurses (95.4\%) exhibited relatively high levels of Depersonalization, and (63.1\%) nurses expressed moderate levels of Emotional exhaustion while 28.2\% reported high Emotional exhaustion level. Conclusion: The study showed that nursing burnout is a substantial problem among nurses working in Governmental and Private Health
\end{abstract}


sector hospitals. Also the study highly revealed that nurses' work conditions and demographic characteristics have a significant effect and crucial role on the nurses feeling of burnout.

\section{Keywords}

Burnout Syndrome, Working Conditions, Private Hospital, Government Hospital

\section{Introduction \& Background}

Burnout is a syndrome that typically characterized by emotional exhaustion, depersonalization, and reduced personal accomplishment (Maslach \& Jackson, 1982). World Health Organization (WHO) recognized burn out as a mental health problem that defined as "a syndrome conceptualized as resulting from chronic workplace stress that has not been successfully managed," (WHO, 2019).

Although burnout pervades every occupation, it is thought to be more prevalent among professionals requiring large amounts of personal involvement and empathy primarily medical \& health care providers (Alqahtani et al., 2019; Alfuqaha \& Alsharah, 2018; Rezaei et al., 2018, and Ribeiro et al., 2014). Indeed, Mbanga et al. (2018) showed that $27 \%$ to $45 \%$ of medical personnel experienced burnout syndrome which usually associated with a high prevalence of depression, suicide, use of psychoactive substances, marital problems and professional dysfunction.

Burnout is a nursing workplace problem due to practice in a complex organizational setting with multiple and, most of the time, conflicting goals. Along with the professional nursing's main job; looking after patients to meet their physical, psychological, spiritual and social needs, a nurse has to handle a wide variety of tasks like documenting patients' health records, attending educational programs, and guiding discussions about the organizational value of patient-centered care within a collaborative multidisciplinary context (Reith, 2018; Jennings, 2008; Abdo et al., 2016; Baishya \& Goswami, 2016). Sometimes due to heavy workload, more varied kind of work demands and less supportive work environment nursing professionals may deplete their high energy level, good health (Baishya \& Goswami, 2016; Grochowska et al., 2018; Hassan, 2015; Konstantinou et al., 2018; Jawabreh, 2016).

Thus, it is important to assess burnout levels among Palestinian nurses especially with the situation of scarcity such studies in Palestine. In fact, few studies carried out within the Palestinian context to assess the burnout syndrome among nurses, primarily focusing on nurses working in the hospitals specialized units such as oncology/Hematology unit, intensive care units or emergency departments, who's their results were variant (Jawabreh, 2016; Hamdan, 2017; Hallaq \& Jondi, 2017; Naerat, 2018).

Abundant studies have documented the tremendous effects of burnout. The 
burnout's manifestations: emotional exhaustion, lack of motivation, and feelings of frustration; may lower nurses' quality of life, performance level, and organizational commitment and increases their intention to leave the job. As well, burnout increases turnover rates and negatively affects the quality of nursing care (Reith, 2018; Jennings, 2018; Jawabreh, Al-Ma'aitah et al., 1999; Mudallal et al., 2017; Van Bogaert et al., 2012).

The nursing profession in Palestine suffers a shortage of nursing workforce, which could be explained as in other countries due to the increase in the nurses' annual turnover rate, the high number of female nurses, and the unattractive work conditions (PNIPH, 2019). In addition to the other work and personal conditions which have strengthened nurses' feelings of dissatisfaction and burnout, such as unrealistic job expectations, poor work conditions, work demands that exceed resources, increased work hazards, and poor autonomy and control over practice (Jawabreh, 2016; Al-Ma'aitah et al., 1999; PNIPH, 2019; Hamdan, 2017; Hallaq \& Jondi, 2017).

The present study aimed to assess burnout among nurses and to determine the difference, if any, in burnout of nurses working in Government and Private Hospitals. In addition, to explore the burnout related precipitating factors and what can be done to manage and prevent burnout.

\section{Materials and Methods}

\subsection{Design, Setting and Population}

A cross-sectional, descriptive, correlational design was used to assess burnout among nurses and explore the difference burnout level among nurses working in Nablus governmental and private hospitals.

The study was conducted among nurses in Nablus district, which considered one of the largest Northern districts in Palestine. Nablus district houses a good number of hospitals/health centers, variously owned by the government, and private sector. During the period of study, there were 420 registered nurses (RNs) practicing in governmental and private hospitals in Nablus. These nurses consisted of males and females, as well as Christians and Muslims.

The four Nablus district hospitals were included in the study which are Nablus Specialty Hospital, Specialized Arab Hospital, which are private hospitals, in addition to Al Watani Hospital and Rafidia Surgical Hospital which are governmental hospitals.

\subsection{Participants and Sampling Techniques}

Out of the 420 nurses in Nablus district hospitals, 195 were selected as study participants using stratified random sampling, distributed equally from the 4 hospitals.

In all participating hospitals, the variables or factors considered in the sampling stratification techniques were the working hospitals wards which are Surgical ward, Medical ward, intensive care unit for Adult and Coronary care pa- 
tients (CCU \&ICU) and Emergency room (ER). Actually, the researchers selected all eligible nurses at each ward included in the strata.

Registered nurses who had at least 6 months of experience in the researched hospital, and who had the ability to read and understand English were included in the study. English is the official language of nursing education in Palestine.

\subsection{Tool \& Measurement}

A questionnaire of three parts: Demographic information, Occupation information and the Maslach Burnout Inventory (MBI) as the best studied measurement of burnout as literature revealed were filled by all participating nurses. The reliability of this questionnaire has been calculated in previous studies.

The demographic questionnaire included age, sex, marital status, occupation, level of education, while the occupational information comprised history of work experience, current and previous positions in hospitals, employment status, work shift situation, and residency.

The MBI questionnaire measures burnout which contained 22 items categorized into three subscales that are: Emotional exhaustion (EE) by ten items, depersonalization (DP) by five items, and personal accomplishment (PA) by seven items.

Emotional exhaustion (EE), describes feelings of being emotionally exhausted because of the work which vary from 0 to 55 (0 - 18: Low, 19 - 26: Moderate, 27 55: High). While the PA subscale describe beliefs of competence and successful achievement at work which vary from 0 to 33 (40 - 50: Low, 34 - 39: Moderate, 0 - 33: High). And the DP subscale describes detached and impersonal treatment of patients and vary from 0 to 30 (0 - 5: Low, 6 - 9: Moderate, 10 - 30: High).

Each of the 22 items asks nurses to describe their feelings on a seven-point scale, ranging from never having those feelings to having those feelings a few times a week. The Likert scale was used including different codes consisting of 0 (never), 1 (several times a year), 2 (once or less a month), 3 (several times a month), 4 (once a week), 5 (several times a week), and 6 (every day).

\subsection{Data Collection \& Analysis}

The study data were assembled by trained research assistants, who were present in the hospital setting during the data collection process to answer any questions related to the study. All eligible registered nurses were invited to participate; where the response rate was very high.

The frequencies, percentages, means, and standard deviations were calculated by using the Statistical Package for the Social Sciences software (SPSS version (22)). Frequencies were used to describe the demographic characteristics and work conditions of the sample. Comparison between the means between governmental and private hospitals to determine any significant differences between variables where inferential statistics were generated at alpha level of $P<$ 0.05 . 


\subsection{Ethical Consideration}

Approval for the study was obtained from the respective study hospitals.

Participating Nurses and study hospitals were briefed and given appropriate orientation on their participation, informed of the purpose of the study, the estimated time required to complete the questionnaires, and their right to withdraw without penalty. Returning the completed questionnaires was considered to signify a written agreement to participate in the study.

To keep anonymity, the questionnaires did not include any information regarding the participant identity, after the nurses completed the questionnaires, the questionnaires were coded with numbers and kept in a sealed box.

\section{Results \& Findings}

A total of 195 registered nurses participated in the study. Approximately 52\% (n $=100$ ) of the participants were male. The mean age of the nurses was 29.78 years $(\mathrm{SD}=6.51)$ and ranged from 22 to 53 years. The nurses had approximately 7.22 mean years ( $\mathrm{SD}=6.20$ ) of experience, and approximately half of the nurses were single $(\mathrm{n}=94,49.2 \%)$. Most of the nurses in the study $(\mathrm{n}=133,67.12 \%)$ had a baccalaureate degree or 3 yrs. diploma and were working either on rotating shifts (A, B, C or day and night) $(\mathrm{n}=136,70 \%)$. The data for this study were collected from hospitals in 2 main health care sectors: $\mathrm{MOH}(\mathrm{n}=94,48.2 \%)$, and private $(\mathrm{n}=101,51.8 \%)$.

The nurses were recruited from different departments: approximately 157 $(80.23 \%)$ were working in general medical and/or surgical departments, and the remaining nurses were working in ICU \& CCU and Emergency Room departments.

Table 1 describes the Demographic \& Working Characteristics of Nablus Hospitals Nurses \& relation with nurses' burnout.

Table 2 shows the results of three dimensions of burnout among nurses in Nablus hospitals.

The results indicated that the majority of the participated nurses (95.4\%) in this study exhibited relatively high levels of Depersonalization, and (63.1\%) of the participated nurses expressed moderate levels of Emotional exhaustion while 28.2\% reported high Emotional exhaustion level. On the other side, high Personal achievement expressed among (90.8\%) of the participated nurses, which implies moderate levels of burnout among the participated nurses.

Table 1 presents the results of MANOVA test conducted which revealed that gender, work shift, department type and hospital type have significant effect on the three burnout dimensions. Values as illustrated describes the relation of Nurses' socio demographic variables and working conditions and nurses' burnout as following: gender, $F_{(3,403)}=12.516, P \leq 0.01$, partial $\eta^{2}=0.081$; work shift, $F_{(3,403)}=3.644, P \leq 0.05$, partial $\eta^{2}=0.026$; department type, $F_{(3,403)}=3.499$, $P \leq 0.01$, partial $\eta^{2}=0.025$; and hospital type, $F_{(6,401)}=8.735, P \leq 0.01$, partial $\eta^{2}$ $=0.061$. 
Table 1. Demographic \& working characteristics of Nablus hospitals nurses \& relation with nurses' burnout $(\mathrm{N}=195)$.

\begin{tabular}{|c|c|c|c|c|c|c|c|c|c|c|c|}
\hline \multicolumn{12}{|c|}{ Nurses' burnout } \\
\hline \multirow{2}{*}{ Variables } & \multicolumn{5}{|c|}{ EEDP } & \multicolumn{6}{|c|}{$\mathrm{PA}$} \\
\hline & $\mathrm{n}(\%)$ & Mean & SD & Mean & $\mathrm{SD}$ & Mean & SD & Wilk $\Lambda$ & $\mathrm{F}$ & $\mathrm{df}$ & Partial $\eta^{2}$ \\
\hline \multicolumn{12}{|l|}{ Socio-demographic variables } \\
\hline Gender & & & & & & & & 0.915 & $12.516^{* *}$ & 3,403 & 0.085 \\
\hline Female & $84(43.07)$ & 30.92 & 12.43 & 14.15 & 6.98 & 33.3 & 10.72 & & & & \\
\hline Male & $111(56.92)$ & 31.93 & 13.15 & 16.69 & 6.46 & 30.95 & 11.22 & & & & \\
\hline Age & & & & & & & & 0.940 & 1.326 & 9 & 0.021 \\
\hline $20-30$ yrs. & $78(40.0)$ & 20.78 & 6.88 & 20.28 & 7.27 & 21.32 & 8.14 & & & & \\
\hline $31-40$ yrs. & $81(41.5)$ & 20.02 & 5.20 & 18.64 & 6.32 & 20.21 & 7.12 & & & & \\
\hline $41-50$ yrs. & $33(16.9)$ & 21.67 & 6.53 & 22.12 & 7.79 & 23.30 & 9.01 & & & & \\
\hline Over 50 yrs. & $3(1.5)$ & 22.33 & 5.86 & 27.00 & 7.94 & 25.67 & 11.15 & & & & \\
\hline Marital status & & & & & & & & 0.981 & 0.854 & 9,401 & 0.006 \\
\hline Single & $96(49.2)$ & 30.32 & 13.32 & 14.63 & 6.71 & 31.91 & 11.41 & & & & \\
\hline Married & $94(48.2)$ & 32.51 & 12.46 & 15.65 & 6.95 & 32.79 & 10.57 & & & & \\
\hline Divorced & $5(2.6)$ & 31.44 & 10.73 & 18 & 7.68 & 30.78 & 12.59 & & & & \\
\hline Widowed & $0(0.0)$ & & & & & & & & & & \\
\hline Level of education & & & & & & & & 0.993 & 0.887 & 3,403 & 0.007 \\
\hline Baccalaureate & $155(79.5)$ & 31.44 & 12.97 & 15.13 & 6.94 & 32.12 & 10.99 & & & & \\
\hline High diploma \& Master & $40(20.5)$ & 32.12 & 11.53 & 16.44 & 6 & 34.26 & 10.92 & & & & \\
\hline \multicolumn{12}{|l|}{ Work conditions } \\
\hline Health care sector (Hospital type) & & & & & & & & 0.881 & $8.735^{\star *}$ & 6,401 & 0.061 \\
\hline $\mathrm{MOH}$ & $94(48.2)$ & 35.27 & 13.83 & 16.34 & 7.7 & 32.23 & 10.3 & & & & \\
\hline Private & $101(51.8)$ & 27.45 & 8.92 & 14.6 & 6.66 & 35.95 & 11.83 & & & & \\
\hline Department & & & & & & & & 0.926 & $3.499^{* *}$ & 3,403 & 0.025 \\
\hline Medical and surgical & $113(58.23)$ & 31.42 & 12.37 & 15.9 & 6.68 & 32.69 & 10.95 & & & & \\
\hline Intensive care units & $44(21.62)$ & 34.77 & 13.79 & 15.93 & 7.01 & 31.46 & 10.51 & & & & \\
\hline Coronary care units & $20(10.57)$ & 28.12 & 12.35 & 12.44 & 8.06 & 32.79 & 11.26 & & & & \\
\hline Emergency rooms & $18(9.58)$ & 28.33 & 12.63 & 12.74 & 4.89 & 31.23 & 12.14 & & & & \\
\hline Work shift & & & & & & & & 0.974 & $3.644^{*}$ & 3,403 & 0.026 \\
\hline Fixed A & $60(30.7)$ & 34.55 & 13.56 & 15.88 & 7.54 & 33.88 & 11.22 & & & & \\
\hline Rotating & $135(69.2)$ & 30.22 & 12.33 & 14.97 & 6.56 & 31.63 & 10.83 & & & & \\
\hline
\end{tabular}


Table 2. Distribution of Maslach burnout inventory scores among Nablus hospitals nurses $(\mathrm{N}=195)$.

\begin{tabular}{cccccc}
\hline \multicolumn{5}{c}{ Burnout } \\
Burnout Dimensions & Mean & SD & Low & Moderate & High \\
\cline { 4 - 6 } & & & $\mathrm{n}(\%)$ & $\mathrm{n}(\%)$ & $\mathrm{n}(\%)$ \\
\hline Emotional exhaustion & 20.64 & 6.14 & $55(28.2)$ & $123(63.1)$ & $17(8.7)$ \\
Depersonalization & 20.01 & 7.10 & $0(0.0)$ & $9(4.6)$ & $186(95.4)$ \\
Personal achievement & 21.26 & 7.95 & $5(2.6)$ & $13(6.7)$ & $177(90.8)$ \\
\hline
\end{tabular}

(ANOVA) tests were conducted to understand the effect of the significant factors on each individual dimension of burnout. The used test results showed that hospital type was the main working condition related variable that affect the EE feeling among participated nurses $(F=11.10, P \leq 0.01)$, which was highest among the nurses who were working in $\mathrm{MOH}$ hospitals. Department type was the other working condition variable that increased the EE feeling among participated nurses ( $F=3.77, P \leq 0.05)$, where nurses working in intensive care units noticed having the highest scores.

ANOVA results indicated also that nurse's work shift was influencing the nursing feeling of EE $(F=3.01, P \leq 0.05)$; whereas nurses who were on fixed A shifts had higher EE scores than those who were rotating on different shifts. Regarding DP, results showed that department type $(F=5.28, P \leq 0.01)$ was significantly associated with Nurses' feeling of $D P(F=5.28, P \leq 0.01)$, and nurses working in intensive care units observed with the highest DP level. Study results indicated that hospital type and gender were significantly associated with the nurses' feeling of PA $(F=4.11, P \leq 0.05) \&(F=2.15, P \leq 0.05)$ respectively (Table 1).

The significant correlation values presented in the results are quite low, which could be explained by the sample size and the design effect, need to be taken account when considering the results of the analysis.

This study showed that nursing burnout is a substantial problem among nurses working in Governmental and Private Hospitals. The study highly revealed that nurses' work conditions and demographic characteristics have a significant effect and crucial role on the nurses feeling of burnout, also it showed that both hospital type and department have significant effect on the nurse feeling of burnout, highlight an area that hospital management can intervene to improve the working condition and reducing nurses' burnout.

\section{Discussion}

To our knowledge, there are a few comprehensive studies on burnout among Palestinian nurses. The results of this study revealed that most Nablus Hospitals nurses exhibit high levels of burnout as reflected by their high levels of EE and 
DP and high reduced PA. This result is consistent with the results of the other few Palestinian studies, highlighting the burnout problem among nurses in $\mathrm{Pa}$ lestine (Jawabreh, 2016; Hamdan, 2017; Hallaq \& Jondi, 2017; Naerat, 2018).

The High nurses' burnout levels within the Palestinian health context could be related to the many challenges that Palestinian nurses face in their daily work at hospital include, poor work conditions, work overload, limited resources and unsupportive management and leadership, as well as to personal and social factors. Adding to that the decreased chances of job advancement which may lead to the emotional exhaustion (Jawabreh, 2016, PNIPH, 2019, Hamdan, 2017, Hallaq \& Jondi, 2017; Naerat, 2018).

The analysis conducted to assess the influence of nurses' work conditions and demographic characteristics on nurses' feelings of burnout, showed that gender as demographic trait, hospital type, department type and work shift as working condition; was the most important factor impacting nursing burnout.

The study demonstrated that female nurses exhibited higher levels of EE and DP and lower levels of PA than male nurses, which is congruent with previous studies. This could be explained by the various responsibilities that the Palestinian female nurse has in addition to her professional responsibility as a nurse including social responsibilities towards home and family (Huntington, et al., 2001; Rubenberg, 2009).

Moreover, it is not culturally accepted for male nurses in Palestineto work in maternity \&pediatrics departments. With the shortage of female nurses; which is a Palestinian health sector prominent issue, nurses had to work in these departments under stressful working conditions including increased workloads and unsatisfactory health outcomes (PNIPH, 2019; Rubenberg, 2009).

The study concluded that although burnout was noticeable among nurses working in the two health care sector hospitals (the type of hospitals), the nurses who were working in $\mathrm{MOH}$ hospitals exhibited the highest levels of EE and DP and the lowest levels of PA in comparison to nurses who were working in private hospitals. This result can be interlinked with the variance in the organizational, administrative and management structures that each health sector own and play crucial role in the behavior, performance of each sector employees (Mataria \& Khoury, 2008).

Other finding presented that burnout was noticeable among nurses working in the intensive care units, where these units' nurses had significantly high levels of both EE and DP. This could be explained due the challenges that ICU nurses face during daily work, as working in (ICUs) entails high work pressure and stress due to witnessing human suffering and the unpredictable nature of the work. As well as the high workload, and the need for professions to manage and cope with the complex health informatics technology (Hallaq \& Jondi, 2017).

Acknowledging the crucial role and significant impact that both hospital type and department have on the nurse burnout, highlight the need for action to be taken to improve these working conditions by improving the working environ- 
ment and enhance the capacity of targeted units (ICUs) by competent human resources and providing necessary support to empower and strengthening working nurse's skills (Quattrin et al., 2006; Spooner-Lane \& Patton, 2007).

Current study showed that nurse's work shift was influencing the nurses' feeling of burnout, whereas nurses who were on fixed A shifts had higher EE scores than those who were rotating on different shifts. Indeed, literature indicated that nurses on fixed A shifts have different and bigger clinical and managerial responsibilities and roles than who are on other shift than $\mathrm{A}$, this workload and he responsibility, making them vulnerable to burnout feeling ( $\mathrm{Ka}$ nai-Pak et al., 2008; Van Bogaert et al., 2009; Hamaideh, 2011).

\section{Conclusion}

In conclusion, this study showed that nursing burnout is a substantial problem among nurses working in Governmental and Private health sector hospitals in Nablus.

The study highly revealed that nurses' work conditions and demographic characteristics have a significant effect and crucial role on the nurses feeling of burnout.

Due to the importance of nursing in the health-care system, and the negative effects on both individuals and organizations as inevitable consequences of burnout which detract from the quality of care; policy-makers should adopt appropriate strategies for turning toxic work environments into healthy workplaces, aiming towards reaching improvements in recruitment and retention of nurses, patient outcomes and quality of care.

\section{Conflicts of Interest}

The authors declare no conflicts of interest regarding the publication of this paper.

\section{References}

Abdo, S. A. M., El-Sallamy, R. M., El-Sherbiny, A. A. M., \& Kabbash, I. A. (2016). Burnout among Physicians and Nursing Staff Working in the Emergency Hospital of University of Tanta, Egypt. EMHJ, 21, 906-915. https://doi.org/10.26719/2015.21.12.906

Alfuqaha, O., \& Alsharah, H. (2018). Burnout among Nurses and Teachers in Jordan: A Comparative Study. Archives of Psychiatry and Psychotherapy, 20, 55-65. https://doi.org/10.12740/APP/80168

Al-Ma'aitah, R., Cameron, S., Armstrong-Stassen, M., \& Horsburgh, M. (1999). Predictors of Job Satisfaction, Turnover, and Burnout in Female and Male Jordanian Nurses. Canadian Journal of Nursing Research, 31, 15-30.

Alqahtani, A. M., Awadalla, N. J., Alsaleem, S. A., Alsamghan, A. S., \& Alsaleem, M. A. (2019). Burnout Syndrome among Emergency Physicians and Nurses in Abha and Khamis Mushait Cities, Aseer Region, Southwestern Saudi Arabia. The Scientific World Journal, 2019, Article ID: 4515972. https://doi.org/10.1155/2019/4515972

Baishya, M., \& Goswami, B. (2016). A Study to Assess Burnout among Nurses of Maternity Department in Gauhati Medical College Hospital, Assam. Open Journal of Psy- 
chiatry \& Allied Sciences, 7, 65-69. https://doi.org/10.5958/2394-2061.2016.00011.2

Grochowska, A., Kubik, B., Romanowska, U., \& Lebica, M. (2018). Burnout among Nurses. Medical Studies, 34, 189-195. https://doi.org/10.5114/ms.2018.78681

Hallaq, R. J., \& Jondi, N. J. (2017). Degrees of Burnout among Nurses Working in the Intensive Care Unit at Hebron Hospitals. Zarqa Journal for Research and Studies in Humanities, 17, 587-599.

Hamaideh, H. (2011). Burnout, Social Support, and Job Satisfaction among Jordanian Mental Health Nurses. Issues in Mental Health Nursing, 32, 234-242. https://doi.org/10.3109/01612840.2010.546494

Hamdan, M. (2017). Burnout among Workers in Emergency Departments in Palestinian Hospitals: Prevalence and Associated Factors. BMC Health Services Research, 17, 407. https://doi.org/10.1186/s12913-017-2356-3

Hassan, M. B. (2015). Assessment of Pediatric Nurses' Burnout in Al-Najaf Al-Ashraf City. International Journal of Scientific and Research Publications, 5, 1-4.

Huntington, R. L., Fronk, C., \& Chadwick, B. A. (2001). Family Roles of Contemporary Palestinian Women. Journal of Comparative Family Studies, 32, 1-19. https://doi.org/10.3138/jcfs.32.1.1

Jawabreh, B. A. (2016). Burnout and the Intention to Leave among Oncology Hematology Nurses in Palestinian Hospitals. Unpublished Master's Thesis, Jerusalem: Al-Quds University.

Jennings, B. M. (2008). Work Stress and Burnout among Nurses: Role of the Work Environment and Working Conditions. In Patient Safety and Quality: An Evidence-Based Handbook for Nurses (Chapter 26). Rockville, MD: Agency for Healthcare Research and Quality.

Kanai-Pak, M., Aiken, L. H., Sloane, D. M., \& Poghosyan, L. (2008). Poor Work Environments and Nurse Inexperience Are Associated with Burnout, Job Dissatisfaction and Quality Deficits in Japanese Hospitals. Journal of Clinical Nursing, 17, 3324-3329. https://doi.org/10.1111/j.1365-2702.2008.02639.x

Konstantinou, A. K., Bonotis, K., Sokratous, M., Siokas, V., \& Dardiotis, E. (2018). Burnout Evaluation and Potential Predictors in a Greek Cohort of Mental Health Nurses. Archives of Psychiatric Nursing, 32, 449-456. https://doi.org/10.1016/j.apnu.2018.01.002

Maslach, C., \& Jackson, S. (1982). Burnout in Health Professions: A Social Psychological Analysis. In G. Sanders, \& J. Suls (Eds.), Social Psychology of Health and Illness (pp. 227-251). Hillsdale, NJ: Lawrence Erlbaum.

Mataria, A., \& Khoury, P. (2008). Public Policies to Enhance Private-Sector Investment and Competitiveness in Tertiary Health Care in the Occupied Palestinian Territory. MAS: Palestine Economic Policy Research Institute.

Mbanga, C. et al. (2018). Determinants of Burnout Syndrome among Nurses in Cameroon. BMC Research Notes, 11, 893. https://doi.org/10.1186/s13104-018-4004-3

Mudallal, R. H., Saleh, M. Y., Al-Modallal, H. M., \& Abdel-Rahman, R. Y. (2017). Quality of Nursing Care: The Influence of Work Conditions, Nurse Characteristics and Burnout. International Journal of Africa Nursing Sciences, 7, 24-30.

https://doi.org/10.1016/j.ijans.2017.06.002

Naerat, I. (2018). Burnout and Psychological Distress among Primary Health Care Nurses and Midwives in North West Bank. Unpublished Master's Thesis, Nablus: An-Najah National University.

Palestinian National Institute of Public Health (PNIPH) (2019). National Human Re- 
sources for Health Observatory: Mapping the Palestinian Health Workforce. http://www.emro.who.int/health-workforce/highlights/palestinian-human-resources-fo r-healh-observatory.html

Quattrin, R., Zanini, A., Nascig, E., Annunziata, M. A., Calligaris, L., \& Brusaferro, S. (2006). Level of Burnout among Nurses Working in Oncology in an Italian Region. Oncology Nursing Forum, 33, 815-820. https://doi.org/10.1188/06.ONF.815-820

Reith, T. P. (2018). Burnout in United States Healthcare Professionals: A Narrative Review. Cureus, 10, e3681. https://doi.org/10.7759/cureus.3681

Rezaei, S., KaramiMatin, B., Hajizadeh, M., Soroush, A., \& Nouri, B. (2018). Prevalence of Burnout among Nurses in Iran: A Systematic Review and Meta-Analysis. International Nursing Review, 65, 361-369. https://doi.org/10.1111/inr.12426

Ribeiro, V. F., Ferreira Filho, C., Valenti, V. E., Ferreira, M., de Abreu, L. C., de Carvalho, T. D., Francisco, N. G. et al. (2014). Prevalence of Burnout Syndrome in Clinical Nurses at a Hospital of Excellence. International Archives of Medicine, 7, 22. https://doi.org/10.1186/1755-7682-7-22

Rubenberg, C. (2009). Women and Politics in Palestinian Women: Patriarchy and Resistance in the West Bank. Boulder, CO: Lynne Rienner Publishers.

Spooner-Lane, R., \& Patton, W. (2007). Determinants of Burnout among Public Hospital Nurses. Australian Journal of Advanced Nursing, 25, 8.

Van Bogaert, P., Clarke, S., Willems, R., \& Mondelaers, M. (2012). Nurse Practice Environment, Workload, Burnout, Job Outcomes, and Quality of Care in Psychiatric Hospitals: A Structural Equation Model Approach. Journal of Advanced Nursing, 69, 1515 1524. https://doi.org/10.1111/jan.12010

Van Bogaert, P., Meulemans, H., Clarke, S., Vermeyen, K., \& Van de Heyning, P. (2009). Hospital Nurse Practice Environment, Burnout, Job Outcomes and Quality of Care: Test of a Structural Equation Model. Journal of Advanced Nursing, 65, 2175-2185. https://doi.org/10.1111/j.1365-2648.2009.05082.x

WHO World Health Organization (2019). Mental Health: Burn-Out an "Occupational Phenomenon": International Classification of Diseases. Geneva: WHO. https://www.who.int/mental_health/evidence/burn-out/en 